cases and the eventual improvement in the eye signs could both be explained in this way, as the granulomas healed.-I am, etc.

Gerald A. MacGregor

Chilworth, Surrey

1 Goolden, A., Williams, E. D., and Thalassinos N. C., Clinical Endocrinology, 1973, 2, 65 . F., Lancet, 1970, 1, 1144 .

Winand, R., and Mahieu, P., Lancet, 1973,

1196.
Mahieu, P., and Winand, R., foumal of Clinical Endocrinology and Metabolism, 1972, 34, 1090

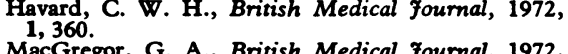

4,116.
James, D. G., Postgraduate Medical foumal, 1973 , James, 86.

Scadding, J. G., Sarcoidosis. London, Eyre and Spottiswood, 1967

Smith, M. J., personal communication

Karlish, A.'J., and MacGregor, G. A., Lancet, $1970,2,330$. Hemmings, I. L., and McLean, D. C., foumal of

Gluck, J., Miller, J. J., and Summerlin, W. T. Fournal of Pediatrics, 1972, 81, 354.

of the European Conference on Sroceedings of the Europed

14 Cohen, J. D. and Clarke, S. W., Proceedings of the Royal Society of Medicine. In press.

5 Leppard, B., and MacGregor, G. A., Proceedings
of the Royal Society of Medicine, 1971, 64, 396.

\section{Sharing the Burden of Certification}

SIR,-One of the infuriations of general prac tice is the task of certification. All too often a patient attends solely to obtain a National Insurance certificate with the words, "The hospital told me to get it from you." In some cases the patient, no doubt, forgot to ask at the hospital. This problem might be eased if hospital doctors asked whether a certificate was needed and if the patient was warned on registering to request one if required.

In certain cases, however, consultants and others refuse to be involved in certification. I think they defend this lack of action on the grounds that it keeps the G.P. informed and involved. In fact it does nothing to inform him, and is his involvement to be characterized by such an idiot task? This week I have had to issue a certificate to a man convalescent from a myocardial infarct who attends hospital monthly and last attended two days before seeing me. The consultant there declined to give him a certificate, referring him to me, but no recent letter from the hospital is available to me to indicate how long the consultant (who is at present managing the medical aspects of the case) wishes him to be off work.

I am sure G.P.s are happy to issue interim certificates for hospital patients, but hospitals should take their sensible share of this work, or they should ensure that the family doctor receives information on patients much more regularly than he does at present.-I am, etc.,

London N.5

C. REISNER

\section{Comparison of Co-trimoxazo'e and Chloramphenicol in Enteric Fever}

SIR,-Schragg and Rubridgel reported high treatment failure and persisting carrier rates in enteric fever patients treated with $c^{-}$ trimoxazole (trimethoprim and sulphamethoxazole). Others, however, have shown co-trimoxazole to be a promising alternative to chloramphenicol.2-4 Our study, involving 72 acute cases of typhoid (54) and para- typhoid fever (18), supports the latter appraisal.

Study patients were admitted to the Abbassia Fever Hospital during the period 1970-2. Criteria for inclusion in the study were either positive blood culture for typhoid or paratyphoid bacillus ( 58 cases) or positive stool culture with significant Widal titre (14 cases). The study patients were assigned to drug groups in a rotational non-selective manner. Co-trimoxazole was administered in doses of $10 \mathrm{mg} / \mathrm{kg}$ body weight daily to 41 patients and chloramphenicol in doses of 50 $\mathrm{mg} / \mathrm{kg}$ daily to 31 . Antibacterial therapy was initiated two days after admission and terminated seven days after defervescence. Patients stayed in the hospital for an average of two months and were followed up in the outpatient clinic for six months. The aetiology, age, and sex distribution and duration of illness before treatment in the two groups were generally comparable.

Patients in the co-trimoxazole group showed a striking and rapid clinical response within 96 hours despite the presence of fever; two-thirds of the patients showed rapid clinical response within 48 hours. The clinical response in the chloramphenicol group was slower and less dramatic, half of the patients showing satisfactory clinical response within five days, $40 \%$ within seven days, and the rest within 10 days. The average number of days required for the patients to become afebrile was 5.5 days in the co-trimoxazole group and 4.5 days in the chloramphenicol group; there was one transient carrier in the former group, and one bacteriological failure, four relapses, and one transient carrier in the latter.

Considering that 40 of the 41 patients treated with co-trimoxazole responded, that only a small number relapsed, and that the average time required for defervescence was only slightly greater than in the chloramphenicol group, co-trimoxazole appears to be as effective in enteric fever therapy as chloramphenicol.-We are, etc.,

ANWAR Hassan MARRAM ERIAN FatMa SaID

Abbassia Fever Hospital

KURT SORENSEN

U.S. Naval Medical Research Unit No. 3 , JOHN SIPPEL

Abbassia

Scragg, J. N., and Rubidge, C. J., British Medical Foumal, 1971, 3 , 738 .

Kamat, S. A., British Medical fournal, 1970, 3, Sardesai, H. V., Karandikar, R. S., and Harshe, R. G., British Medical fourmal, 1973, 1, 82 . 3, 323.

\section{Heartburn of Pregnancy}

SIR,-Your leading article on this subject (19 May, p. 378) failed to stress what we considered to be the real point of our paper - that incompetence of the pyloric sphincter allows reflux of bile which in turn causes heartburn by irritating the lower end of the oesophagus. You did briefly touch upon this, but then dismissed it, going on to talk about "antacid preparations that float on the surface of the gastric contents" etc.

If reflux of bile is the cause of pregnancy heartburn, then antacids are very unlikely to improve matters. We are currently trying to cure this often very upsetting symptom with an acid mixture, and will report in due course.-I am, etc.,

Mill Road Maternity Hospital,

R. D. Atray Liverpool

1 Atlay, R. D., Gillison, E. W., and Horton, A. L., fourmal of Obstetrics and Gynaecology of the
British Commonwealth, 1973, 80, 63 .

Vocational Training and the R.C.G.P.

SIR,-There is no doubt that the Royal College of General Practitioners has done admirable work in pioneering vocational training for general practice, though some doubt may be expressed as to the validity of the excessively introspective methods at present in vogue in that college (for example, the use of "role play" and other techniques). One might be excused for concluding that sociological and environmental medicine had been invented by the R.C.G.P. What is, however, much more disturbing is the nearmonopoly position now being reached by this particular group of doctors, so that G.P.s ready and willing to teach are being subtly constrained to attend Governmentsponsored courses heavily dominated by the ideas of the R.C.G.P. Before long it may well be impossible for any doctor to be accepted as a teacher of undergraduates unless he himself is a M.R.C.G.P. and has attended courses guided by the college.

Is this not to make the R.C.G.P. equivalent in its power over G.P.s to the Royal Colleges of Physicians with regard to medical specialists and the Royal Colleges of Surgeons with regard to surgeons? The latter colleges are statutorily recognized as specialists' colleges with monopolist rights over the appointments of specialists. I find it difficult to see how general practice, by its very nature, can ever be a specialty on the same terms as those represented by the other royal colleges. I believe I am not alone in viewing with disquiet the way in which the R.C.G.P. is deploying an increasingly powerful position and not only in the field of vocational training. "Must be an M.R.C.G.P." is a label one would not like to see attached to advertisements for the best G.P. jobs.

That the R.C.G.P. is doing a great deal of good for general practice is beyond dispute. That it should dominate it is another matter. Such a trend would in my view be detrimental to that variety of skills and methods which family doctoring embodies and lead to an unhealthy stratification along certain narrow and preconceived lines. It should be resisted.-I am, etc.,

Huddersfield

S. L. HENDERSON SMITH

Significance of Milk pH in Newborn Babies

SIR,-Dr. W. A. Cox and others (5 May, p. 301) have contested our finding that cow's milk is bacteriostatic for Escherichia coliwhen titrated to pH 7.40 (2 December 1972, p. 515) and we have been obliged to repeat our study.

The following milks were selected for trial: Carnation evaporated milk (strength 1/2) Similac, and Cow and Gate. A 20-ml sample of each milk was titrated to pH $7 \cdot 20$ and pH 7.40 by the addition of $4.2 \%$ sodium bicarbonate. An equal quantity of sterile 
Mean Milk pH and Colony Counts of Specific E. coli

\begin{tabular}{|c|c|c|c|c|c|c|c|}
\hline \multicolumn{2}{|c|}{ Milk } & \multicolumn{6}{|c|}{ Count after Incubation (organisms/ml) } \\
\hline Group & pH & 1 hour & 2 hours & 3 hours & 4 hours & 5 hours & 6 hours \\
\hline$\underset{\text { III }}{\text { II }}$ & $\begin{array}{l}6 \cdot 58 \\
7 \cdot 20 \\
7 \cdot 40\end{array}$ & $\begin{array}{l}5.1 \times 10^{3} \\
5 \times 10^{3} \\
3 \times 10^{3}\end{array}$ & $\begin{array}{l}9.3 \times 10^{3} \\
8 \times 10^{3} \\
5 \times 10^{3}\end{array}$ & $\begin{array}{l}4.6 \times 10^{4} \\
3 \times 10^{4} \\
9.3 \times 10^{3}\end{array}$ & $\begin{array}{l}8.6 \times 10^{4} \\
7 \times 10^{4} \\
2 \times 10^{4}\end{array}$ & $\begin{array}{l}5.3 \times 10^{8} \\
1.6 \times 10^{5} \\
4.6 \times 10^{4}\end{array}$ & $\begin{array}{l}3 \times 10^{8} \\
4.6 \times 10^{5} \\
7.8 \times 10^{4}\end{array}$ \\
\hline \multicolumn{2}{|c|}{$\begin{array}{l}\text { P (Group I \& II) } \\
\text { P (Group I \& III) }\end{array}$} & $\begin{array}{l}>0.1 \\
>0.1\end{array}$ & $\begin{array}{l}<0.02 \\
<0.01\end{array}$ & $\begin{array}{l}<0.05 \\
<0.01\end{array}$ & $\begin{array}{l}<0.05 \\
<0.01\end{array}$ & $\begin{array}{l}<0.01 \\
<0.01\end{array}$ & $\begin{array}{l}<0.01 \\
<0.01\end{array}$ \\
\hline
\end{tabular}

water was added to untitrated samples

Viable $E$. coli counts were made on $6 \mathrm{ml}$ of milk at the reconstituted $\mathrm{pH}$ and at $\mathrm{pH}$ values of $7 \cdot 20$ and $7 \cdot 40$. The specific $E$. coli 0111/B4 inoculum was prepared from a 12 hour actively growing culture in tryptone water. Each milk sample was inoculated with approximately $2 \times 10^{2}$ organisms and inoubated for six hours at $37^{\circ} \mathrm{C}$. Counts were made hourly in triplicate on blood agar plates by the method of Bullen et al. ${ }^{1}$

The results shown in the table indicate a bacteriostatic effect of titrated milk which is more marked after six hours and most obvious at a $\mathrm{pH}$ of 7.40 . The bacteriostatic effect appears to be pH-related as it was originally produced in milk after an addition of electrolyte-free THAM (trometamol) as well as sodium bicarbonate.

We trust that the disagreement regarding these findings will not detract from the main point of the original article-namely, that the ability of titrated milk to colonize an infant's bowel with lactobacilli rather than $E$. coll may provide some protection against gastroenteritis.-We are, etc.,

\section{C. HARRISO} G. PEAT

Department of Paediatrics and Child Health, University of Cape Town, Cape Town

1 Bullen, J. J., Wilson, A. B., and Cordiner, K., fournal
$\mathbf{8 2}, 383$.

\section{Traveller's Ankle}

SIR,-Many people have had to give up long journeys by coach or aeroplane on account $\alpha$ the ankle swelling and discomfort caused. Passengers in cars or trains seem to be immune, and it would appear that it must be the unrelieved knee flexion that is to blame. Similar conditions, as in a crowded air-raid shelter or over-long spent with the knees tightly flexed over the rail of a desk chair (shelter leg; steamer leg) occasionally gave rise to deep venous thrombosis. These cases were often attributed to imagined kinking of the popliteal vein with obstruction. But no evidence of any such obstruction can be seen when the knee is flexed during phlebography. Alternative hypotheses are therefore proposed.

Veins extensively intercommunicate and offer a variety of alternative routes to the venous blood. When blood flow throureh them is at a minimum thore must of ${ }^{\circ}$ en be segments of vein of which the contents are completely stagnant. The veins in which this would be expected most to occur in the "coach" position would be the numerous wide sinusoidal veins in the calf muscle. These are indeed the veins in which deep venous thrombosis most commonly starts.

The usual cause of ankle oedema is locally raised intracapillary pressure. This rises some 80 or $90 \mathrm{~mm} \mathrm{Hg}$ on changing from a recumbent to a standing position, or about $60 \mathrm{~mm}$
Hg on adopting the "coach" position. But activating the calf pump reduces this by about $50 \%$. This gives any oedema that has formed an opportunity to absorb. Even the little movement carried out in a train or a car is evidently enough. I therefore suggest that sufferers from "traveller's ankle" should exercise their toes and ankles quite briefly, say every half-hour. This simple manoeuvre could also hope substantially to reduce the incidence of deep venous thrombosis in association with operation, with childbirth and even with "medical" illness. To the question "Why does not spontaneous thrombosis occur at night?" the answer was surely implicit in a recent television programme on sleep; for it seems that during natural sleep we move a great deal without knowing it Obviously no single doctor is going to have enough material for significant analysis; but if those who try my suggestion care to write to me about the result I will write again to this journal in 12 months' time.-I am, etc.

\section{H. Daintree Johnson}

Department of Surgery, London $\mathbf{W} .12$

\section{Prevention of Pulmonary Embolism}

SIR,-Though we share most of the views on pulmonary embolism expressed by $\mathrm{Mr}$ F. S. A. Doran in his letter (9 June, p. 612) we must question his statement that the measurement of fibrin/fibrinogen degradation products is impractical. The methods he mentions, gel chromatography and the seria dilution protamine sulphate test, are indeed tedious and difficult. Fibrin/fibrinogen degradation products may, however, be easily and accurately measured using the latex test ${ }^{1}$ and the tanned red cell haemagglutination immunoassay. ${ }^{2}$ Excellent commercial kits for these estimations are available from Burroughs Wellcome. Commercial preparations of lyophilized staphylococci are also available from Sigma Chemicals or Hoechst Pharmaceuticals for the staphylococci clumping test, ${ }^{3}$ which can easily be performed in 10 minutes by any technician. We have found that 60-70 such tests can be completed in two hours.

We recommend that $\mathrm{Mr}$. Doran try one of these simple tests. We are sure that he will find them an invaluable diagnostic aid in pulmonary embolism.-We are, etc.

D. R. B. JONES

I. M. C. MACINTYR

C. V. RUCKIEY

General Surgical Unit,

Western General Hospital,

1 Garvey, M. B., and Black, J. M., Fourmal of Clinical Pathology, 1972, 25, 680.
Merkey, C., Kleiner, G. J., and Johnson, A. J. Merskey, C., Kleiner, G. J., and Johed, 1966, 28, 1. 3 Leavelle, D. E., Mertens, B. F., Bowie, E. J. W. and Owen, C. A., America Royal Postgraduate Medical School
Erythrocyte Sedimentation Rate in Hyperlipidaemia

SIR,-I believe that my colleagues and $I^{1}$ have already published the clue to the question posed by Professor L. E. Böttiger and others (23 June, p. 681) as to why the E.S.R. is raised in many hyperlipidaemic subjects. These authors correctly hypothesize that it is a reflexion of hidden vascular disease. We were able to show that the level of serum fibrin monomer, which is the first breakdown product of fibrinogen and an indicator of in vivo thrombin formation, is directly related to the beta-lipoprotein level in diabetic subjects. In another study (to be published elsewhere) we have also found that serum fibrin monomer levels are high in youngish subjects experiencing their first coronary thrombosis, and furthermore that platelet factor 4 levels, a real indicator of in vivo platelet breakdown, ${ }^{2}$ are related to serum fibrin monomer levels and also to the serum cholesterol.

It seems to be a matter of opinion as to which factors are really important in determining the E.S.R. I am convinced that Lipinski et $a l .^{3}$ were correct when they demonstrated that it is the level of serum fibrin monomer that determines the E.S.R. and that variations in other proteins, "agglomerins," and lysolecithin are not the basic explanation.

I therefore envisage a sequence whereby hyperlipidaemia will lead to enhanced platelet aggregation, with platelet factor 4 release causing in vivo thrombin formation, which will mean increased fibrin monomer levels. In turn the increased fibrin monomer could lead to increased fibrinooen synthesis, as had indeed been shown for fibrin degradation products which, when increased, lead to increased fibrinogen synthesis. ${ }^{5}$ This would be the explanation of the increased fibrinogen levels and increased fibrinogen synthesis rates in atherosclerotic subjects, and very likely would also account for the observation that fatty acid levels can influence fibrinogen synthesis. ${ }^{6}-\mathrm{I}$ am, etc.,

Deparment of Medicine,

E. N. WARDLE

Royal Victoria Infirmary,

1 Wardle, E. N., Piercy, D. A., and Anderson, J., Postgratuate Metical Fournal, 1973, 49. 1 . Bowie Fuster, V.. Karmier. F. J., Cash. J. D., Bowie,

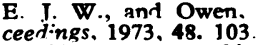

3 Lipinki, B . Wornwski. K., Mysliwiec, M.. and Farhiszeweki ${ }_{\text {R. Thromhosis et Diathesis }}$ Hnemnmhacira. 1969, 21. 196

Wardle E. N., British Diabetic Association Sum5 Borri, V, and Parini. A. Thromboris et D athesis Haemorrhagira, 1973. 396 \%

Piloeram. L. O., and Pirkart, L. R. Fournal of Atherosclerosis Research, 1968, 8, 155 .

\section{Consultant Surgeons and Vasectomy}

SIR,-Mrs. Marjorie Waite's thorough and fascinating paper (16 June, p. 6?9), deals with various aspects of vasectomy, including estimates of the number of operations performed in 1970. This information would be much more interesting and meaningful if it could be related to known demand for the operation; no attempt is made in the paper to assess this.

Our experience is relevant here. This is a practice of five doctors, providing general medical services wholly to N.H.S. patients. We offer vasectomy free of charge to registered patients, and have done so since 